\title{
Calculation of pressure loss and critical velocity for slurry flows with additive agents in vertical polyethylene pipelines
}

\author{
Yevhen Semenenko ${ }^{1}$, Stepan Kril ${ }^{2}$, Olha Medvedieva ${ }^{1}$, Nina Nykyforova, ${ }^{3, *}$ and Larysa \\ Tatarko $^{4}$ \\ ${ }^{1}$ Institute of Geotechnical Mechanics named by N. Poljakov of National Academy of Sciences of \\ Ukraine, 49005, Dnipro, Simferopolska Str., 2a, Ukraine \\ ${ }^{2}$ Institute of Hydromechanics of National Academy of Sciences of Ukraine, 02000, Kyiv, Maria Capnist \\ Str., 8/4, Ukraine \\ ${ }^{3}$ National Metallurgical Academy of Ukraine, 49600, Dnipro, Haharina Ave., 4, Ukraine \\ ${ }^{4}$ Ukrainian State University of Chemical Technology, Haharina Ave. 8, Dnipro, 49600, Ukraine
}

\begin{abstract}
The method of determination of parameters of hydrotransport of solid polydisperse materials in vertical pipelines is offered. The reasons of discrepancy between estimated and observed data when using A. Smoldyrev's method for calculation of hydraulic gradient and critical velocity in vertical steel pipelines are analysed. Particularly nonapplicability of Velicanov principle to hydrotransport of solid materials in vertical pipelines is proved and contribution of particles fall velocity to the value of complementary hydraulic gradient in vertical pipelines is estimated. Suggested formulas for calculation of hydraulic gradient and critical velocity in vertical pipelines are multipurpose because they may be used for calculation of hydrotransport parameters in steel and polymeric vertical pipelines with using of friction reducing agents and without it. The method for parameters calculation of solid materials hydrotransport in vertical polymeric pipelines is first offered. Elaborated formulas ensure also increasing of accuracy of calculations.
\end{abstract}

\section{Introduction}

Pressurized hydrotransport plants with vertical main pipelines are widespread at mineral processing factories and in technologies of underwater mineral production. Vertical main pipelines account for $80 \%$ of pressure pipes of pump installation at dressing works and their part may reach $100 \%$ during underwater mining operations [1, 4]. The most promising methods for reaching reduction of energy consumption in pressurized hydrotransport systems at mineral processing factories with vertical main pipelines are the replacement of steel pipes by pipes fabricated of polyethylene and the adding of friction reducing agents to slurries. Both methods reduce hydraulic resistance and as a result of this make slurry thickening or plant pipeline elongation possible without an installation of additional pumps. However, using of

*Corresponding author: ninanik@ua.fm 
these methods at mineral processing factories is restricted by absence of reliable calculation procedures of hydrotransport parameters namely of hydraulic gradient and critical velocity for vertical pipelines. Calculation of these parameters is important as material delivery is possible only under overcritical regimes, but hydraulic gradient value determines pump capacity. On the basis of examination of known calculation procedures of critical velocity and hydraulic gradient during slurry flow in vertical pipelines the A. Smoldyrev's calculation procedure was modernized as well as the research of pressurized hydrotransport regimes in polyethylene vertical pipelines using friction reducing agents and without them was carried out $[1,4,9]$.

It is necessary to take into account that concept of critical velocity is different for horizontal and vertical pipes. Critical velocity in horizontal pipeline is minimal velocity of slurry flow, below which deposition of solid particles on the pipe bottom and flow in transition regimes become possible. Critical velocity of material transportation in vertical pipeline is a minimal velocity that ensures movement of solid particles in upward flow without backward motion in a wall part of flow and without fluidized bed forming. The results of investigations [3 - 9] show that a cross pulsation of velocity takes part in suspension during transportation of solid particles in horizontal pipelines and its value doesn't exceed $15 \%$ of axial velocity, but only averaged component of axial velocity takes part in this process in a vertical pipeline. Therefore rated ratios of main hydraulic characteristics must be considered separately for horizontal and vertical sections of given pipeline. Thereby, known dependences adapted to calculation of hydrotransport parameters in horizontal polyethylene pipes can't be used for vertical pipes.

\section{Methods}

In the former Soviet Union the most detailed research of hydrotransport of bulk materials in vertical pipelines was carried out by [7]. He processed experimental results in the form of a functional dependence of two quantities (Fig. 1, Fig. 2)

$$
I=\frac{i-i_{0}}{i_{0} S} \quad f r=\frac{(V-w)^{2}}{g D A r}
$$

where $I$ - relative complementary hydraulic gradient in steel vertical pipelines; $i$ slurry hydraulic gradient; $i_{0}$ - water hydraulic gradient; $S$ - bulk concentration of fine fraction particles; $f r$ - modernized Froude criterion; $V$ - average discharge velocity of slurry; $w$ - rate of constrained fall of small fraction particles; $g$ - gravitational acceleration; $D$ - pipeline diameter; $A r$ - the parameter of Archimedean solids.

The results of this research also allowed an offer of formulas for determination of hydraulic gradient and hydrotransportation critical velocity

$$
i=\left\{\begin{array}{ll}
i_{0}\left(1+\frac{10 g D A r}{(V-w)^{2}} S\right), & 1<f r<10 \\
i_{0}(1+A r S), & f r>10
\end{array} V_{c r}=w+3 \sqrt{g D A r S},\right.
$$

where $V_{c r}$ - critical velocity of hydrotransportation in steel vertical pipeline.

However, comparison of calculation results using formula (2) with initial experimental data shows significant deviation of theoretical calculations from empirical values (Fig. 2). Chosen method of error estimation assumes that maximum precision of proposed dependence is realized when points on the diagram are located strictly on the bisector lined from coordinate origin. We can see on the Figure 2 that bulk of the points is found rather 
far from bisector. It means that Smoldyrev's calculation procedure badly agrees with the experiment. It is quite possible that imperfection of accessible at that time computing machinery was the reason for such error. Perhaps the same reason induced power exponent 2 in the formula (2) instead of 1.79. Noncoincidence of power exponents partly explains why Archimedean parameter remains in the formula for calculation of hydraulic gradient when $f r>10$ although it must be cancelled. An attempt to include fall velocity of transporting particles into formulas also may be the reason for an error. Hydrotransport is put into practice when average velocities are 10 or $20 \%$ up on the critical velocity. So such expression may be used for calculation of hydraulic gradient in critical regime:

$$
i_{c r}=2.11 \frac{v^{0.135}(S A r)^{0.933}}{g^{0.068} D^{0.202}} \frac{(1+\omega)^{1.865}}{3.347}, V_{c r}=3 \sqrt{g D A r S}(1+\omega), \omega=\frac{w}{3 \sqrt{g D A r S}},
$$

where $i_{c r}-$ critical hydraulic gradient in steel vertical pipeline; $v$ - kinematic coefficient of slurry viscosity.

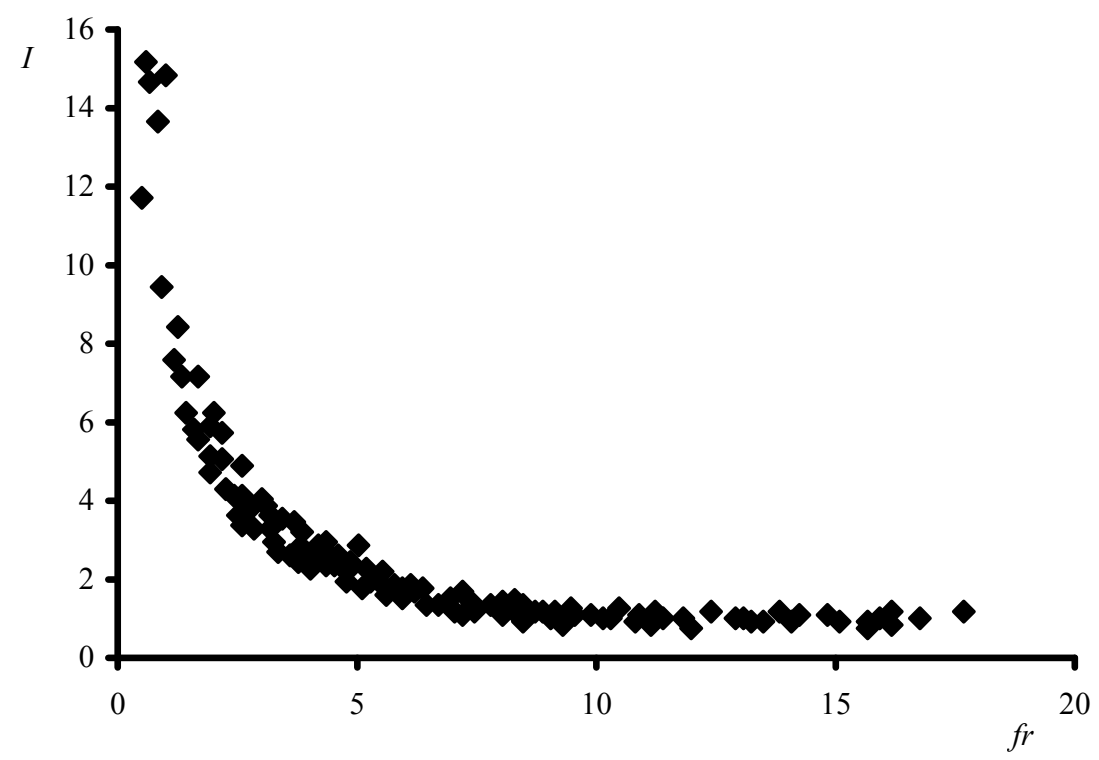

Fig. 1. Experimental results of hydrotransport research in steel vertical pipes [7].

It is evident from formulas (3) that fall velocity impact depends on ratio $\omega$ value and its contribution to critical velocity may be neglected when

$$
\omega \leq 0.1 \text {. }
$$

It is necessary to know the dependence of fall velocity on diameter and density of transporting particles to estimate a possibility of constraint (4) satisfaction. Smoldyrev's calculation procedure of hydrotransport parameters in horizontal pipes specifies transporting material clustering into three fractions (fine, medium and coarse). This classification was given by [2] and further was extended by A. Smoldirev to the case of solid particles transportation by pressurized turbulent flows. V. Goncharov recommended formulas for fall velocity calculation for every fraction and this allows transformation of constraint (4) to the form common for all fractions (Table 1, Fig. 3, Fig. 4): 


$$
S \geq S_{*}, \quad S_{*}=\frac{1}{1+\frac{A}{\delta^{m}}}, \quad \delta=\frac{d}{D}
$$

where $S_{*}$ - slurry concentration, beginning with which constraint (4) is satisfied; $\delta$ relative diameter of solid particles; $d$-weighted average diameter fraction particles.

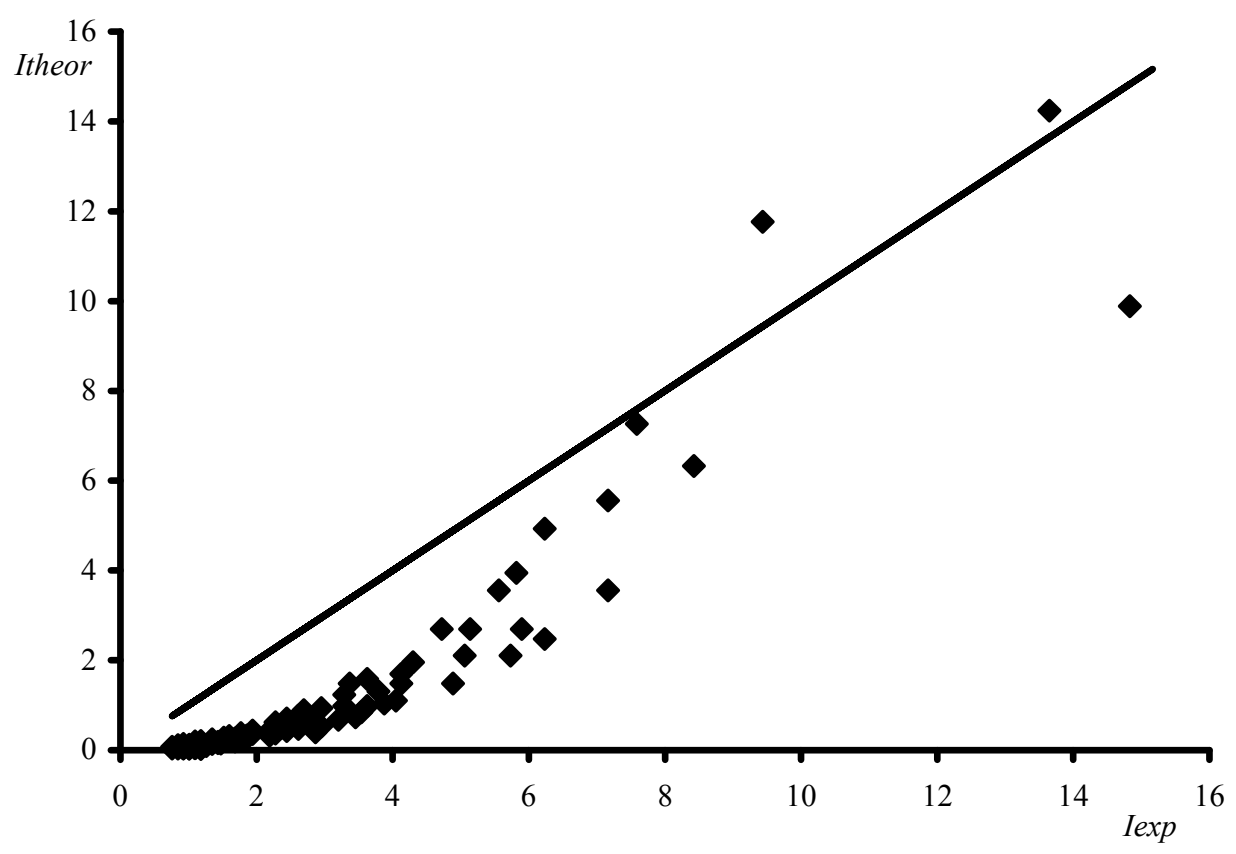

Fig. 2. Comparison of calculation results using Smoldyrev's procedure with his experimental results.

Table 1. Formulas for calculation of coefficients in the expression for $S_{*}$.

\begin{tabular}{|c|c|c|}
\hline \multirow{2}{*}{ Fractions } & Formulas for calculation of coefficients \\
\cline { 2 - 3 } & $A$ & $m$ \\
\hline$d \leq 0.15 \mathrm{~mm}$ & $A=\frac{27.701}{A r G m} ; G m=\frac{g D^{3}}{v^{2}} ;$ & 4 \\
\hline $0.15 \leq d \leq 3 \mathrm{~mm}$ & $A=\frac{400}{A r^{3} \sqrt{G m(1+T)^{2}} ; T=\frac{t-25.99}{35.36 d} ;}$ & 2 \\
\hline$d>3 \mathrm{~mm}$ & $A=0.034 ;$ & 1 \\
\hline
\end{tabular}

Note: $t$ - water temperature in ${ }^{\circ} \mathrm{C}$.

Estimation of intervals of $S_{*}$ value changing (Fig. 3, Fig. 4, Fig. 5) for characteristic intervals of changing of parameters entering into the expressions (5) shows that impact of fall velocity may be neglected for particles with diameter $d \leq 3 \mathrm{~mm}$ in significant changing interval of their relative diameter. Therefore transportation of solid particles in vertical pipelines occurs with velocities considerably exceeding fall velocity of particles. So the presence of this quantity in the denominator of formula (2) doesn't introduce significant contribution to value of complementary hydraulic gradient in vertical pipelines. 


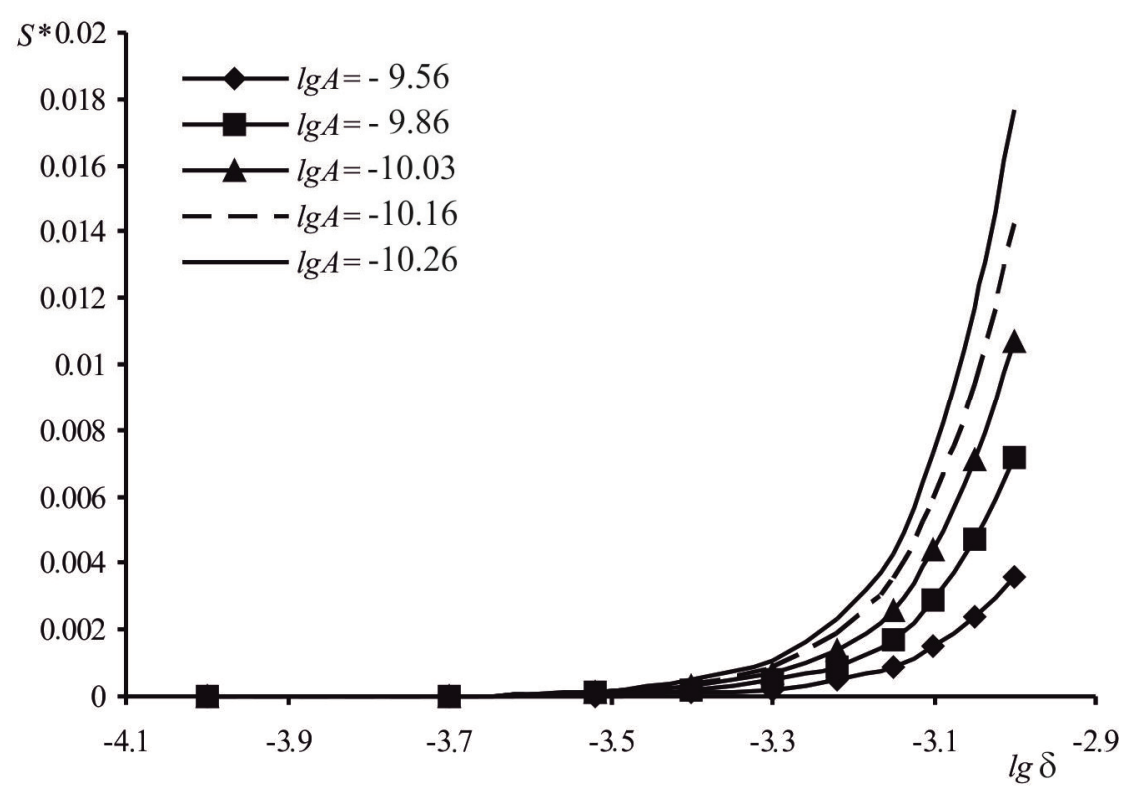

Fig. 3. Dependence of $S_{*}$ on relative diameter of particles with $d \leq 0.15 \mathrm{~mm}$ when changing their density and pipeline diameter.

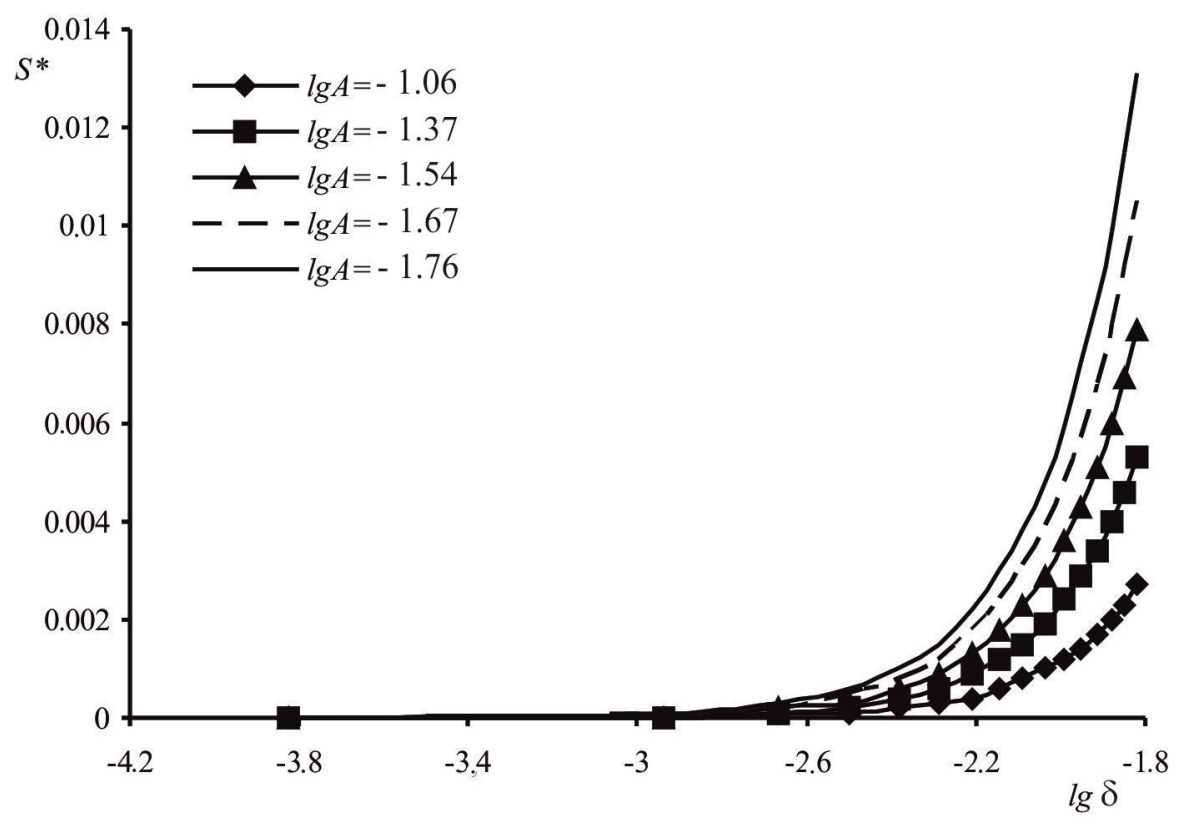

Fig. 4. Dependence of $S_{*}$ on relative diameter of particles with $0.15<d<3 \mathrm{~mm}$ when changing their density and pipeline diameter.

This fact allows elimination of fall velocity of transporting particles from expression for Froude number when processing experimental data (Fig. 1) and approximation of this dependence as (Fig. 5, Fig. 6) 


$$
I=\frac{9.42}{F r^{0.89}}, \quad F r=\frac{V^{2}}{g D A r},
$$

where $\mathrm{Fr}$ - Froude number.

Comparison of Figure 2 and Figure 6 shows that formula (6) describes experimental data more accurately and may be recommended for calculation of hydraulic gradient in vertical pipes under different conditions in such form (Table 2):

$$
i=i_{0}+\frac{M A r^{0.89}}{0.212} \frac{v^{m} V^{0.22-m}}{g^{0.11} D^{0.11+m}} S, \quad i_{0}=\frac{M v^{m} V^{2-m}}{2 g D^{1+m}} .
$$

Table. 2. Values of coefficients $M$ and $m$ for different flow conditions.

\begin{tabular}{|l|c|c|}
\hline \multicolumn{1}{|c|}{ Flow conditions } & $M$ & $m$ \\
\hline Steel pipe without adding of friction reducing agent to slurry & 0.771 & 0.135 \\
\hline Polyethylene pipe without using of friction reducing agent & 0.240 & 0.273 \\
\hline Polyethylene pipe with using of friction reducing agent & $0.144 \mathrm{e}^{347.04 C}$ & $25.046 C+0.172$ \\
\hline
\end{tabular}

Note: $C$ - mass fraction of friction reducing agent in slurry.

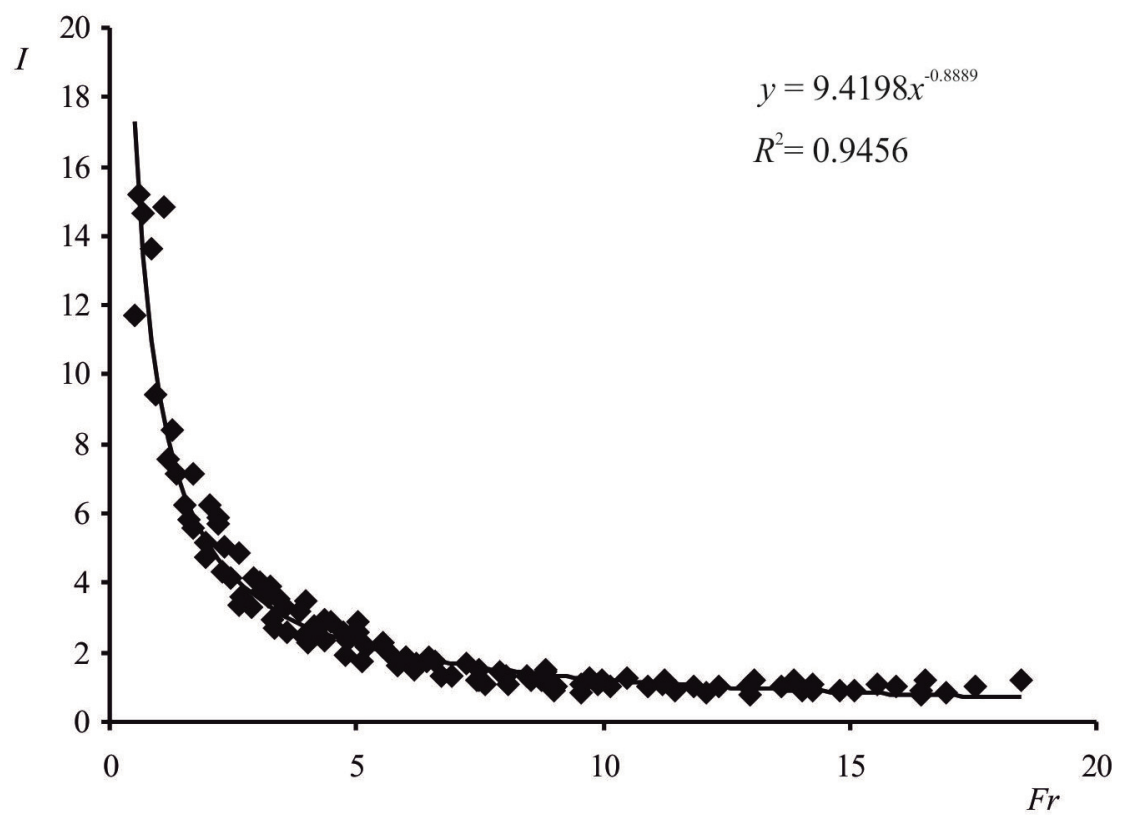

Fig. 5. Approximation of [7] experimental results neglecting fall velocity of solid particles.

Changing of expression for calculation of hydraulic gradient requires correction of formula (2) for calculation of critical velocity. This formula was obtained by A. Smoldyrev from corresponding dependence for calculation of hydraulic gradient on the basis of [8] principle

$$
\frac{i_{c r}-i_{0}^{c r}}{i_{c r}}=K_{V},
$$

where $i_{0}^{c r}$ - hydraulic gradient in steel vertical pipeline during water flow with critical 
velocity; $K_{V}-$ Velicanov constant.

Inserting expression (7) into condition (8) and performing simple transformations we can obtain the dependence

$$
V_{c r}=\sqrt{2 g D A r}\left[5.083 \frac{1-K_{V}}{K_{V}} S\right]^{\frac{9}{16}}
$$

For estimation of Velicanov constant value let's repeat the same procedure with Smoldirev's dependences. Inserting expression (2) into condition (8) we can obtain after transformations

$$
V_{c r}=w+\sqrt{10 \frac{1-K_{V}}{K_{V}}} \sqrt{g D A r S} .
$$

It follows from formulas (10) and (2) that expression (9) transforms into

$$
V_{c r}=3.326 \sqrt{g D A r} S^{\frac{9}{16}} .
$$

Formulas (2) and (11) differ in power exponent when constraint (4) is satisfied and this introduces an error in value of critical velocity. The greatest relative error is observed when values of slurry concentration don't exceed $20 \%$.

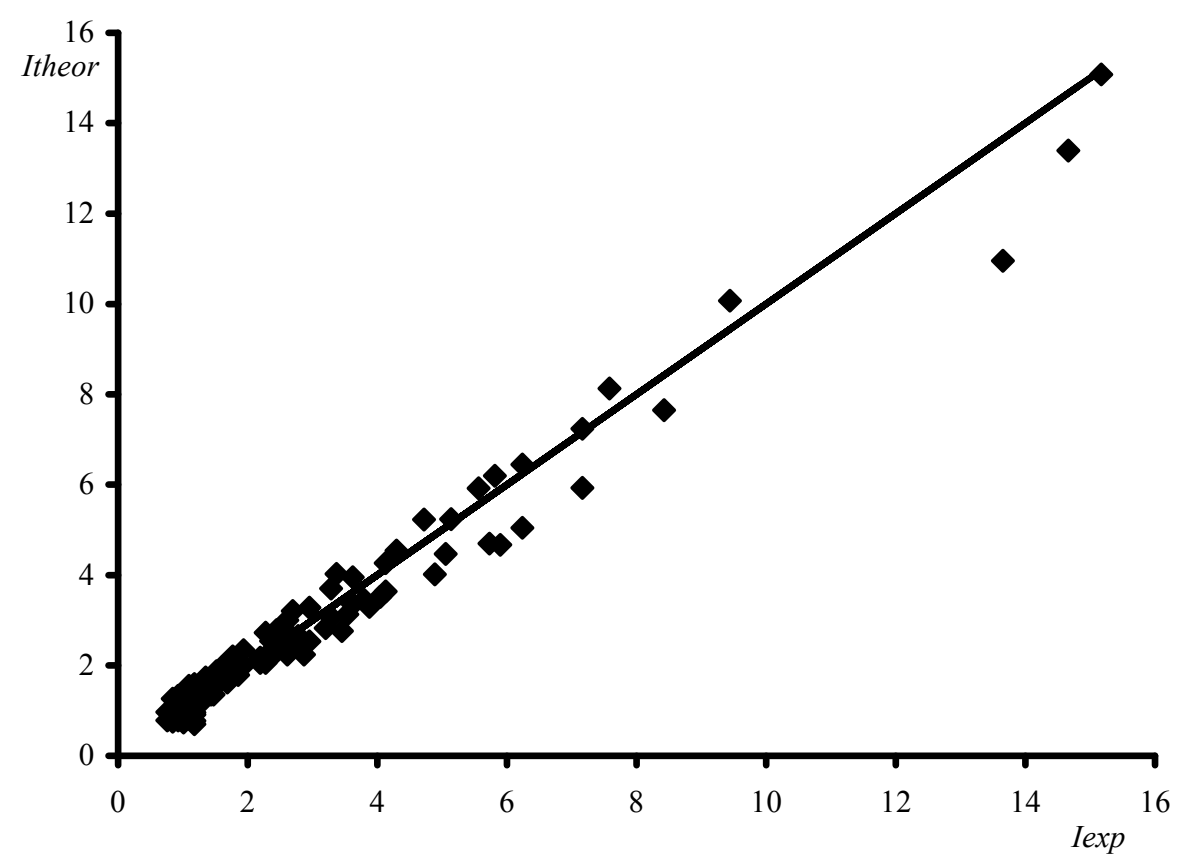

Fig. 6. Comparison of calculation results using formula (6) with experimental data.

It is evident from formula (11) that critical velocity doesn't depend on pipeline material if Velicanov principle is used. But such conclusion contradicts to considered process physics. The reason of this paradox consists in the following. Velicanov principle was 
formulated within the scope of the gravitational theory of movement of alluviums in horizontal flows. It explains the process of sedimentation of particles on the bottom of pipeline. In the case of flow in vertical pipelines this principle is not applicable because a moment of critical regime occurrence is determined by stopping of transporting material particles in flow wall zones. So substantiation of conditions of flow critical regime occurrence in vertical pipelines requires comparison of fall velocity of particles with friction velocity. Friction velocity characterizes shearing stresses on the pipe wall [4]

$$
w(1+k C) \leq \sqrt{\frac{0.25 g D i}{1+A r S}},
$$

where $k$ - constant of flocculation process of transporting material particles when adding friction reducing agent to slurry [3].

When formula (7) was substituted into condition (12) the inequality for determination of hydrotransportation critical velocity in vertical pipelines was obtained. Then transforming magnitudes to dimensionless form and performing corresponding transformations we have obtained formula for calculation of hydrotransportation critical velocity in vertical pipelines under different flow conditions (Table 2):

$$
V_{c r}=2-m \frac{1+A r S}{0.212} \Omega \sqrt{g D}, \quad \Omega=\frac{1.7}{M} \frac{(1+k C)^{2} w^{2}}{v^{m} g^{1-\frac{m}{2}} D^{1-\frac{3 m}{2}}}-\frac{A r^{0.89} S}{1+A r S} .
$$

Thereby, formulas (7) and (13) allow calculation of parameters of hydrotransport of solid polydisperse materials in vertical pipes fabricated of different materials and for hydrotransport in the presence of friction reducing agents.

\section{Conclusions}

1. First the method is offered for parameters calculation of solid materials hydrotransport in vertical polymeric pipelines.

2. Suggested formulas for calculation of hydraulic gradient and critical velocity during hydrotransport of solid polydisperse material in vertical pipelines are multipurpose. These formulas are applicable to hydrotransport in steel and polymeric pipelines with using of friction reducing agents and without it.

3. Suggested formulas ensure increasing of accuracy of hydrotransport parameters calculations in vertical pipelines and this allows reduction of energy and water consumption during hydrotransport.

\section{References}

1. Baranov, Yu.D., Blyuss, B.A., Semenenko, Ye.V., Shuryigin, V.D. (2006). Obosnovanie parametrov $i$ rezhimov rabotyi sistem gidrotransporta gornyih predpriyatiy. Dnepropetrovsk: Novaya ideologiya

2. Goncharov, V.N. (1962). Dinamika ruslovyih potokov. Leningrad: Gidrometeoizdat

3. Nikiforova, N.A. (2008). Substantiation of parameters of hydrotransportation process of minerals with using of friction reducing agents, Abstract of Ph.D. dissertation, Geotechnical and Mining Mechanics, Institute of Geotechnical Mechanics named by N. Poljakov of National Academy of Sciences of Ukraine, Dnepropetrovsk, Ukraine

4. Semenenko, Ye.V. (2011). Nauchnyie osnovyi tehnologiy gidromehanizatsii otkryitoy razrabotki titan-tsirkonovyih rossyipey. Kyiv: Naukova dumka 
5. Semenenko, Ye.V., Nikiforova, N.A., Tatarko, L.G. (2013). Calculation of operating modes of hydrotransport complexes with main pipelines composed of polyethylene and steel pipes sections. Geotehnicheskaya mehanika [Geo-Technical Mechanics], 111, 140152

6. Shvabauer, V., Gvozdev, I., Gorilovskiy, M. (2006). Calculation of hydraulic pressure loss in plastic pipeline. Zhurnal Polimernyie trubyi, 1, 46-52

7. Smodlyrev, A.Ye. (1980). Truboprovodnyiy transport. Moskva: Nedra

8. Velicanov, M.A. (1958). Ruslovoy protsess. Moskva: Gostehizdat

9. Vitushko, O.V, Nykyforova, N.A., Semenenko, Ye.V. (2009). The improvement of calculation method of hydrotransport parameters of polydisperse materials. Metallurgicheskaya $i$ gornorudnaya promyishlennost [Metallurgical and Mining Industry], 6, 66-69 